\title{
Comparison of Cesarean Section and Normal Vaginal Delivery Using Entonox Inhalation in Terms of Oxidative Stress Indices in Newborns and Mothers
}

\author{
Katayon Vakilian ${ }^{1 *}$, Akram Ranjbar ${ }^{2}$
}

\begin{abstract}
Objectives: Introduction: Review of articles point out that the route of delivery may cause oxidative stress. Since management of labor is of great importance for healthy childbearing, the present study was performed to compare cesarean section (CS) and normal vaginal delivery (NVD) through Entonox inhalation in terms of oxidative stress indices in mode of delivery.

Materials and Methods: Sixty women undergoing CS and 60 women undergoing painless labor using Entonox gas were included in the study after obtaining a written informed consent. Three tests including lipid peroxidation, total thiol molecules (TTMs), and ferric reducing ability of plasma (FRAP) assay were performed. To this end, venous blood samples $(5 \mathrm{~mL})$ were obtained from the mothers at the end of the second stage of labor or after surgery. The same indices were measured for $5 \mathrm{~mL}$ of blood sample taken from the umbilical artery of the infants. Descriptive (means) and analytical (independent t test) tests were employed for data analysis. Results: Mean maternal lipid peroxidation level in the CS and Entonox groups were $5.798 \pm 4.210$ and $5.105 \pm 2.892 \mathrm{nmol} / \mathrm{mm}$, respectively $(P=0.544)$. TTMs were $0.2846 \pm 0.2632$ and $0.2656 \pm 0.2437 \mathrm{mmol} / \mathrm{mm}$ in the CS and Entonox groups $(P=0.687)$. Moreover, mean scores of FRAP were $0.766 \pm 0.516$ and $1.057 \pm 0.626 \mathrm{nmol} / \mathrm{mm}$ in the CS and Entonox groups, respectively $(P=0.007)$. However, oxidative stress indices of the infants were not different between 2 groups $(P>0.05)$.

Conclusion: Since total antioxidant capacity in the CS group was lower compared to the Entonox group, it seems that maternal antioxidant defense decreases. Thus, Entonox can be used safely from the perspective of oxidative stress indices.

Keywords: Oxidative stress, Cesarean section, Entonox, Newborn
\end{abstract}

\section{Introduction}

According to some studies, fear and pain of normal vaginal delivery (NVD) is the first $(1,2)$ or second (3) reason for cesarean section (CS). Labor pain is a complex, subjective, and multidimensional response to the sensory stimuli during delivery. Labor pain and methods to relieve it are great concerns for pregnant women $(2,4)$. The perspective of medical care systems on labor and labor pain management is progressively relied on anesthetic and analgesic drugs; although there are certain limitations in their medical approval (5).

Nitrous oxide has been known as an anesthetic and analgesic for more than 200 years (6). Moreover, $\mathrm{N}_{2} \mathrm{O}$ is used in pains associated with wound dressing (7), labor pain (8), and labor anxiety (9). $\mathrm{N}_{2} \mathrm{O}$ is the only inhaled gas that lowers labor pain and is used by midwives in Iran (8).

Although 21 studies in a systematic review revealed reduced pain as a result of $\mathrm{N}_{2} \mathrm{O}$ administration, that study affirmed that $\mathrm{N}_{2} \mathrm{O}$ cannot be definitively suggested for diminishing pain; as the quality of those studies was under question (10). In some studies, side effects such as dizziness, diarrhea, and vertigo were reported (11).

Studies on different methods of labor such as CS $(4,8)$ and painless labor reported different findings regarding maternal oxidative stress. For instance, a study on selective $\mathrm{CS}$ and its comparison with a control group (vaginal labor) indicated that the content of degradation products from lipids was greater in women undergoing CS than that in the control group (12).

Oxidative stress results from an imbalance between the production of free radicals and active oxygen species on the one hand and their neutralization by antioxidant defense system on the other hand (13). The existence of mitochondria-rich cells and free DNAs in the placenta (14-16) can affect the abundant production of free radical species. These free radicals play an important role in the health of reproductive system. Oxygen radicals influence ovarian production of estrogens, corpus luteum function, and oocyte maturation. The main complications of oxidative stress include impaired function of the endothelial cells, hypertension (17), clinical symptoms of preeclampsia $(18,19)$, intrauterine growth restriction, and low birth weight (20-22). Since no study has compared the indices of oxidative stress in various delivery methods such as CS and NVD using Entonox, this article was conducted to measure the above-mentioned indices. 


\section{Materials and Methods}

In this case-control study, the sample size was calculated to be 60 for each group (CS and Entonox groups; with power of $80 \%, a=0.05$, and odds ratio: 3 ) (23). Convenience sampling method was employed to select the subjects from the labor ward and operating room of Taleghani hospital, Arak, Iran.

After obtaining written informed consent, venous blood sample $(5 \mathrm{~mL})$ was obtained from the mothers at the end of the second stage of labor. The inclusion criteria for the mothers in the Entonox group were: no acute or chronic pregnancy complications, singleton pregnancy, and Entonox inhalation. The blood samples were collected and sent to the laboratory for freezing and centrifugation at the end of the first stage of labor. Moreover, $5 \mathrm{~mL}$ of umbilical-cord blood was obtained after delivery.

In the CS group, $5 \mathrm{~mL}$ blood was obtained from the mothers post-operative. Blood samples were also obtained from the infants instantly after birth, before placental expulsion, similar to the infants in the Entonox group. Drugs used for CS and general anesthesia included 1 $\mathrm{mg} / \mathrm{kg}$ of succinylcholine, $5-7 \mathrm{mg} / \mathrm{kg}$ of sodium thiopental, $10 \mathrm{mg}$ of atracurium besylate, isoflurane, and 50\% oxygen. In case of any congenital defects or Apgar score of less than 8 , the neonates were excluded from the study.

After transferring the samples to the laboratory, $\mathrm{Hu}$ method was used to assess the oxidation rate of the proteins, measuring the total thiol molecules (TTMs) of plasma. Oxidative stress decreases TTMs. Their measurement was performed based on the $\mathrm{Hu}$ calorimetric method using 2,2 dithionitrobenzoic acid and Ellman's reagent. 2,2 dithionitrobenzoic acid reacts with thiol molecules and produces a yellow complex with maximum absorbance at $412 \mathrm{~nm}$ (23).

The SatoH method and thiobarbituric acid (TBA) were used to measure lipid peroxidation, the absorbance of which was calculated at $532 \mathrm{~nm}$ (24). Ferric reducing ability of plasma (FRAP) assay was used to measure serum total antioxidant capacity. This method measures the ability of plasma in reducing ferric ions. The diminution of ferric to ferrous ions in an acidic $\mathrm{pH}$ in the presence of specific reagents creates a blue complex, which can be measured by spectrophotometer at $593 \mathrm{~nm}(25,26)$. To analyze the data, descriptive (means) and analytical (independent $t$ test) statistics were used in SPSS, version 17.0.

\section{Results}

Mean ages of the mothers were $23.72 \pm 4.25$ years and $24.08 \pm 4.08$ years in the CS and Entonox groups, respectively $(P=0.544)$. In addition, mean gestational ages were $38.97 \pm 0.71$ weeks and $39.06 \pm 0.80$ weeks in the CS and Entonox groups, respectively $(P=0.502)$. There was no significant difference between the weight of newborns in the CS $(3160 \pm 326.33 \mathrm{~g})$ and Entonox $(3140 \pm 268.8 \mathrm{~g})$ groups $(P=0.690)$. None of the mothers in the Entonox group received oxytocin during labor.

As shown in Table 1, the means of lipid peroxidation in the mothers in the cesarean and Entonox groups were $5.79 \pm 4.21$ and $5.10 \pm 2.89(P=0.301)$, respectively, while for infants these values were $5.14 \pm 2.80$ and $6.06 \pm 3.40$ $(P=0.111)$, respectively. The difference between the groups was not significant. Other oxidative stress indices of samples are provided in Table 1.

\section{Discussion}

Oxidative stress occurs when the balance is not maintained between antioxidants and oxidants; in other words, when oxidants prevail over antioxidants. Many factors in pregnancy and childbirth affect the oxidative stress in mothers and infants including number of deliveries (27), and mothers' illnesses such as diabetes (28) and preeclampsia $(29,30)$. It should be mentioned that the above factors were among the exclusion criteria of the study to assess the influence of delivery with an emphasis on painless vaginal delivery without intervention. The findings of this study showed that except for the maternal total antioxidant capacity, the other oxidative stress indices were not significantly different between 2 groups. Total antioxidant capacity of the mothers who received Entonox was higher compared to those undergoing CS.

A study on 20 women in 3 groups of NVD, regional anesthesia (RA), and general anesthesia (GA) showed that

Table 1. Mean of Oxidative Stress Indices in Mothers and Newborns in 2 Modes of Delivery

\begin{tabular}{|c|c|c|c|c|c|}
\hline Antioxidant Indices & & Delivery Mode & $\mathbf{N}$ & Mean \pm SD & $P$ Value $^{\text {a }}$ \\
\hline \multirow{2}{*}{ Lipid peroxide, nmol/mm } & \multirow{2}{*}{ Mother } & CS & 60 & $5.79 \pm 4.21$ & \multirow{2}{*}{0.301} \\
\hline & & Entonox & 60 & $5.10 \pm 2.89$ & \\
\hline \multirow{2}{*}{ Lipid peroxide, $\mathrm{nmol} / \mathrm{mm}$} & \multirow{2}{*}{ Newborn } & CS & 60 & $5.14 \pm 2.80$ & \multirow{2}{*}{0.111} \\
\hline & & Entonox & 60 & $6.06 \pm 3.40$ & \\
\hline \multirow{2}{*}{ TTM, $\mathrm{mmol} / \mathrm{mm}$} & \multirow{2}{*}{ Mother } & CS & 60 & $0.28 \pm 0.26$ & \multirow{2}{*}{0.687} \\
\hline & & Entonox & 60 & $0.26 \pm 0.24$ & \\
\hline \multirow{2}{*}{ TTM, $\mathrm{mmol} / \mathrm{mm}$} & \multirow{2}{*}{ Newborn } & CS & 60 & $0.28 \pm 0.25$ & \multirow{2}{*}{0.293} \\
\hline & & Entonox & 60 & $0.23 \pm 0.22$ & \\
\hline \multirow{2}{*}{$\mathrm{FRAP}, \mathrm{mmol} / \mathrm{mm}$} & \multirow{2}{*}{ Mother } & CS & 60 & $0.76 \pm 0.51$ & \multirow{2}{*}{0.007} \\
\hline & & Entonox & 60 & $1.05 \pm 0.62$ & \\
\hline \multirow{2}{*}{ FRAP, $\mathrm{nmol} / \mathrm{mm}$} & \multirow{2}{*}{ Newborn } & CS & 60 & $0.93 \pm 0.76$ & \multirow{2}{*}{0.443} \\
\hline & & Entonox & 60 & $1.02 \pm 0.54$ & \\
\hline
\end{tabular}

andipendent $t$ test $<0.05$ significant. 
the level of lipid degradation products in mothers was higher in the GA group $(5.99 \pm 1.50 \mathrm{nmol} / \mathrm{mL})$ and lower in the RA group $(4.85 \pm 1.50 \mathrm{nmol} / \mathrm{mL})$. In conclusion, the least amount of oxidative stress indices, both for women and their newborns, was found in the group giving birth under regional (epidural) analgesia $(P<0.001)(31)$. In the study of Vakilian et al, comparing the elective cesarean delivery and uncomplicated vaginal delivery showed that lipid peroxidation and thiol were significantly higher in vaginal delivery group than the ones in the elective cesarean delivery group. However, there was no significant discrepancy between 2 delivery methods as far as total antioxidant capacity was concerned (32). These 2 studies were not consistent with our study. The inconsistent results are due to the varied comparisons, as the above studies compared cesarean deliveries and various types of anesthesia, while this study compared cesarean using general anesthesia and Entonox gas. Increased lipid oxidation in the studies is caused by damage to cells, as membranes of cells contain lipid and the increased lipid damage indicates cell damage. Reduced thiol groups indicate cell damage in blood cells, as $95 \%$ of glutathione is in red blood cells that helps in maintenance of hemoglobin form. They are powerful antioxidants, which play an important role in maintaining pregnancy and preventing oxidative stress (33). There was no significant difference between lipid peroxidation and thiol groups in 2 delivery methods in this study.

As many studies show the increased oxidative stress in cesarean deliveries (31-32), physicians should be cautious in providing oxygen concentration (34). In this regard, one study was conducted on 30 pregnant women to evaluate the effect of oxygen concentration during CS under spinal anesthesia on lipid peroxidation. In one group, the mothers received $21 \%$ oxygen. In another groups (2 and 3 ), mothers received $35 \%$ and $60 \%$ oxygen, respectively. Malondialdehyde (MDA) was measured before and after CS in maternal and umbilical venoarterial blood samples. MDA basal level was lower in group 1 than that in groups 2 and 3. Fetal lipid products were also significantly higher in umbilical venoarterial blood samples in group 3 when compared to group 1. Maternal MDA concentration in the group receiving higher oxygen concentration was higher. MDA level of the infants in groups 2 and 3 also increased (34).

Our study showed no significant difference in the oxidative stress indices between infants born through CS and NVD using Entonox.

A study on Nigerian females aimed at studying the impact of delivery method on the severity of oxidative stress in umbilical cord blood showed no significant changes in oxidative stress indices. However, total antioxidant capacity in blood of infants with emergency delivery was higher than that in infants born via vaginal delivery, and lipid peroxide content in vaginal delivery was lower than that in emergency cesarean delivery (35), which was consistent with the findings of our study.

Another study was conducted on lipid peroxide levels in umbilical cord bloods of 45 infants born via emergency cesarean delivery, vaginal delivery, and elective cesarean delivery (15 infants in each group) in Turkey. It showed some significant changes in increased lipid peroxide levels in the emergency and vaginal deliveries as compared with the elective cesarean delivery in umbilical cord blood (36). Their result was not consistent with the findings of this study. However, a study on umbilical artery blood samples showed that lipid peroxidation in uncomplicated NVD was higher than that in CS. Therefore, the results showed that high amounts of free radicals in the fetus resulted from the function of the labor type (37). Another study pointed out that the level of serum glutathione was greater in mothers with NVD than that in the umbilical cord of their infants.

Furthermore, the level of thiol groups was lower in both mothers and their infants in CS versus NVD (38). Oxidative stress status in infants is of great importance, as antioxidant defense system is weak in the fetal and neonatal period and it is unable to confront risky conditions. Therefore, fetal complications such as intrauterine growth restriction (IUGR) and brain damages among the complications may occur (39-41).

The current study was performed on term neonates. Future studies are recommended to probe the correlation between oxidative stress and preterm labor. Furthermore, this study discussed the enzymatic indices of oxidative stress; it is proposed to conduct studies on the nonenzymatic indices of oxidative stress including vitamin indices.

\section{Conclusion}

Since the total antioxidant capacity was lower in CS than that in the Entonox delivery, it seems that CS decreased antioxidant capacity in mothers, however outcomes for newborns were identical. It seems that antioxidant capacity of mothers does not affect antioxidant capacity index in their newborns.

\section{Conflict of Interests}

Authors declare that they have no conflict of interests.

\section{Ethical Issues}

Approval code was obtained from the Ethics Committee of Arak University of Medical Sciences, Arak, Iran (Code No. 154).

\section{Financial Support}

Financial support Was provided by Arak University of Medical Sciences.

\section{Acknowledgements}

The authors would like to thank Deputy of Research of Arak University of Medical Sciences, and all those who 
cooperated in this study.

\section{References}

1. Van der Gucht N, Lewis K. Women's experiences of coping with pain during childbirth: a critical review of qualitative research. Midwifery. 2015;31(3):349-358. doi:10.1016/j. midw.2014.12.005

2. Hajian S, Vakilian K, Shariati M, Ajami ME. Perspective of Pregnant Women, midwives, obstetrics and gynecology specialists and anesthetists to delivery: a qualitative study. Payesh Health Monit. 2010;10(1):39-48.

3. Solehati T, Rustina Y. Benson Relaxation Technique in Reducing Pain Intensity in Women After Cesarean Section. Anesth Pain Med. 2015;5(3):e22236. doi:10.5812/ aapm.22236v2

4. Imani F, Entezary SR, Alebouyeh MR, Parhizgar S. The maternal and neonatal effects of adding tramadol to $2 \%$ lidocaine in epidural anesthesia for cesarean section. Anesth Pain Med. 2011;1(1):25-29. doi:10.5812/ kowsar.22287523.1271

5. Johanson R, Newburn M, Macfarlane A. Has the medicalisation of childbirth gone too far? BMJ. 2002;324(7342):892-895.

6. Cury Y, Picolo G, Gutierrez VP, Ferreira SH. Pain and analgesia: The dual effect of nitric oxide in the nociceptive system. Nitric Oxide. 2011;25(3):243-254. doi:10.1016/j. niox.2011.06.004

7. Pediani R. Patient administered inhalation of nitrous oxide and oxygen gas for procedural pain relief. World Wide Wounds. 2003. http://www.worldwidewounds.com/2003/ october/Pediani/Entonox-Pain-Relief.html.

8. Talebi H, Nourozi A, Jamilian M, Baharfar N, EghtesadiAraghi P. Entonox for labor pain: a randomized placebo controlled trial. Pak J Biol Sci. 2009;12(17):1217-1221. doi:10.3923/pjbs.2009.1217.1221

9. Manouchehrian N, Bakhshaei MH. Nitrous oxide effect on relieving anxiety and pain in parturients under spinal anesthesia for caesarean section. Anesth Pain Med. 2014;4(2):e16662. doi:10.5812/aapm.16662

10. Clarke R, Daly L, Robinson K, et al. Hyperhomocysteinemia: an independent risk factor for vascular disease. $\mathrm{N}$ Engl J Med. 1991;324(17):1149-1155. doi:10.1056/ nejm199104253241701

11. Rooks JP. Safety and risks of nitrous oxide labor analgesia: a review. J Midwifery Womens Health. 2011;56(6):557-565. doi:10.1111/j.1542-2011.2011.00122.x

12. Mutlu B, Aksoy N, Cakir H, Celik H, Erel O. The effects of the mode of delivery on oxidative-antioxidative balance. J Matern Fetal Neonatal Med. 2011;24(11):1367-70. doi: $10.3109 / 14767058.2010 .548883$

13. Cindrova-Davies T, Yung HW, Johns J, et al. Oxidative stress, gene expression, and protein changes induced in the human placenta during labor. Am J Pathol. 2007;171(4):1168-1179. doi:10.2353/ajpath.2007.070528

14. Toescu V, Nuttall SL, Martin U, Kendall MJ, Dunne F. Oxidative stress and normal pregnancy. Clin Endocrinol (Oxf). 2002;57(5):609-613.

15. Saker M, Soulimane Mokhtari N, Merzouk SA, Merzouk H, Belarbi B, Narce M. Oxidant and antioxidant status in mothers and their newborns according to birthweight. Eur J Obstet Gynecol Reprod Biol. 2008;141(2):95-99. doi:10.1016/j.ejogrb.2008.07.013
16. Hung TH, Lo LM, Chiu TH, et al. A longitudinal study of oxidative stress and antioxidant status in women with uncomplicated pregnancies throughout gestation. Reprod Sci. 2010;17(4):401-409. doi:10.1177/1933719109359704

17. Guerin P, El Mouatassim S, Menezo Y. Oxidative stress and protection against reactive oxygen species in the preimplantation embryo and its surroundings. Hum Reprod Update. 2001;7(2):175-189.

18. Mistry HD, Wilson V, Ramsay MM, Symonds ME, Broughton Pipkin F. Reduced selenium concentrations and glutathione peroxidase activity in preeclamptic pregnancies. Hypertension. 2008;52(5):881-888. doi:10.1161/ hypertensionaha.108.116103

19. Haque SK, Siddiqui MU, Islam N, Moin S. Erythrocyte markers of oxidative stress in higher age-group preeclamptic and normal pregnant mothers. Hypertens Pregnancy. 2010;29(1):69-81. doi:10.3109/10641950902849868

20. Potdar N, Singh R, Mistry V, et al. First-trimester increase in oxidative stress and risk of small-for-gestational-age fetus. Bjog. 2009;116(5):637-642. doi:10.1111/j.14710528.2008.02096.x

21. Toy H, Camuzcuoglu H, Arioz DT, Kurt S, Celik H, Aksoy N. Serum prolidase activity and oxidative stress markers in pregnancies with intrauterine growth restricted infants. J Obstet Gynaecol Res. 2009;35(6):1047-1053. doi:10.1111/ j.1447-0756.2009.01063.x

22. Min J, Park B, Kim YJ, Lee H, Ha E, Park H. Effect of oxidative stress on birth sizes: consideration of window from mid pregnancy to delivery. Placenta. 2009;30(5):418423. doi:10.1016/j.placenta.2009.02.007

23. $\mathrm{Hu} \mathrm{ML}$. Measurement of protein thiol groups and glutathione in plasma. Methods Enzymol. 1994;233:380-5.

24. Satoh K. Serum lipid peroxide in cerebrovascular disorders determined by a new colorimetric method. Clin Chim Acta. 1978;90(1):37-43.

25. Vakilian K, Ranjbar A. Associations of oxidative stress indices in infants born via natural delivery with Entonox exposure. J Babol Univ Med Sic. 2015;17(10):34-8. [Persian].

26. Benzie IF, Strain JJ. Ferric reducing/antioxidant power assay: direct measure of total antioxidant activity of biological fluids and modified version for simultaneous measurement of total antioxidant power and ascorbic acid concentration. Methods Enzymol. 1999;299:15-27.

27. Golalizadeh F, Shobeiri F, Ranjbar A, Nazari M. Maternal Parity and Blood Oxidative Stress in Mother and Neonate. Biotechnology Health Sciences. 2016;3(1):e34165. doi:10.17795/bhs-34165

28. Djordjevic A, Spasic S, Jovanovic-Galovic A, Djordjevic R, Grubor-Lajsic G. Oxidative stress in diabetic pregnancy: SOD, CAT and GSH-Px activity and lipid peroxidation products. J Matern Fetal Neonatal Med. 2004;16(6):367372. doi:10.1080/14767050400018270

29. Diaz-Castro J, Florido J, Kajarabille N, et al. A new approach to oxidative stress and inflammatory signaling during labour in healthy mothers and neonates. Oxid Med Cell Longev. 2015;2015:178536. doi:10.1155/2015/178536

30. Ghazavi A, Ranjbar A, Vakilian K. Comparison of oxidative stress in preeclampsia, normal pregnancy and non-pregnant women. Koomesh. 2006;8(1):41-46.

31. 12. Mehmetoglu I, kart A, Caglayan O, Capar M, Gokce R. Oxidative stress in mothers and their newborns in different types of labour. Turk J Med Sci. 2002;32(5):427-429. 
32. Vakilian K, Ranjbar A, Zarganjfard A, et al. On the relation of oxidative stress in delivery mode in pregnant women; a toxicological concern. Toxicol Mech Methods. 2009;19(2):94-99. doi:10.1080/15376510802232134

33. Kharb S. Low whole blood glutathione levels in pregnancies complicated by preeclampsia and diabetes. Clin Chim Acta. 2000;294(1-2):179-183. doi.org/10.1016/S00098981(99)00253-3

34. Singh V, Hooda S, Dahiya K, Sharma R. Effect of different inspired oxygen concentrations during caesarean section under spinal anaesthesia on maternal and foetal oxygenation and lipid peroxidation. Bombay Hosp J. 2006;48(4):561-566.

35. Adekanle DA, Oparinde DP, Atiba AS, Akintayo AA. Effect of different modes of delivery on cord blood oxidative stress markers. Int J Biomed Sci. 2013;9(4):249-254.

36. Gulbayzar S, Arica V, Hatipoglu S, Kaya A, Arica S, Karatekin G. Malondialdehyde level in the cord blood of newborn infants. Iran J Pediatr. 2011;21(3):313-319.
37. Biswas S, Bhattacharyya S, Ghosh C, Banerjee S, Mukherjee $\mathrm{K}$, Basu A. Assessment of oxidative stress and antioxidant status among newborns in relation to mode of delivery. International Journal of Current Research and Review. 2014;6(7):65-73.

38. Raijmakers MT, Roes EM, Steegers EA, van der Wildt B, Peters WH. Umbilical glutathione levels are higher after vaginal birth than after cesarean section. J Perinat Med. 2003;31(6):520-522. doi:10.1515/jpm.2003.079

39. Biri A, Bozkurt N, Turp A, Kavutcu M, Himmetoglu O, Durak I. Role of oxidative stress in intrauterine growth restriction. Gynecol Obstet Invest. 2007;64(4):187-192. doi:10.1159/000106488

40. Buonocore G, Perrone S, Bracci R. Free radicals and brain damage in the newborn. Biol Neonate. 2001;79(3-4):180186. doi:10.1159/000047088

41. Dani C, Cecchi A, Bertini G. Role of oxidative stress as physiopathologic factor in the preterm infant. Minerva Pediatr. 2004;56(4):381-394.

Copyright $\odot 2018$ The Author (s); This is an open-access article distributed under the terms of the Creative Commons Attribution License (http://creativecommons.org/licenses/by/4.0), which permits unrestricted use, distribution, and reproduction in any medium, provided the original work is properly cited. 